\title{
Delivering Superior Customer Perceived Value in the Context of Network Effects
}

\author{
Fan-Chen Tseng, Kainan University, Taiwan \\ Ching-I Teng, Chang Gung University, Taiwan \\ David M. Chiang, National Taiwan University, Taiwan
}

\begin{abstract}
Network effect refers to the phenomenon that the value of connecting to a network depends on the present number of customers connected to that network. The self-reinforcement characteristic of the network effect strengthens the strong firms and weakens the weak firms. In the extreme form, network effects may produce a winner-take-all market. Therefore, competitive strategies are critical for companies in markets characterized by network effects. To succeed in the market, a firm must be able to deliver superior value to customers compared to its competitors. This study proposes a conceptual model for describing the market situations characterized by network effects. Based on this model, this study clarifies how companies can deliver superior customer value in the context of network effects. This study proposes two major approaches: increasing total customer value and reducing total customer costs. Various practical methods are proposed for implementing these two approaches.
\end{abstract}

Keywords: e-commerce strategy; network externalities; IT management; value networks

\section{INTRODUCTION}

The rise of information technologies has dramatically changed the whole world. Businesses are not excluded from the trend. In information economies, network effects play a crucial role in e-business competitions. The "larger gets larger" mechanism guarantees a theoretical natural "monopoly" (the sole market leader owning a nearly $100 \%$ share of a market) for the winner, urging e-businesses such as netenabled organizations and value Webs to take advantage of network effects.
Network effects refer to the value of connecting to a network depending on the number of customers already connected to the network. Larger networks are more beneficial to users than smaller ones. New users thus tend to prefer larger networks to smaller ones, resulting in a phenomenon of larger networks growing continuously. Networks can be physical, such as telephone networks, or virtual, such as the networks of the members of a Web site. Industries in which network effects exist include information products, communication 
networks, durable goods, and services. Typical examples are telephone, image phone, e-mail, videotape, computer operating system, office software, TV game player, surgical operation, computer language, and computer keyboard.

Network effects pervade the network sector such as the telecommunication industry and the information (hardware and software) industry. With the popularization of electronic commerce, network effects also are critical in online auctions and information exchange businesses such as e-marketplaces or online employment Web sites.

It is well known that network effects can tilt the market toward the largest player and produce a natural monopoly (Chou \& Shy, 1990; Farrell \& Saloner, 1992; Katz \& Shapiro, 1986). For example, "Microsoft's dominance is simply a manifestation of the network externality (effects) which relentlessly drives computer software to standardization" (Choi, Stahl, \& Whinston, 1997, p. 4). Therefore, competitive strategies in markets characterized by network effects are important for e-businesses to strive to be the largest. Chen, Chen, and Wu (2005) provided a Simonian perspective on e-business regularities that guide e-businesses to gain lasting competitive advantage in the digital economy.

Previous research on this area has focused on inefficiencies in social welfare (the gap between the actual and the optimal social welfare) resulting from network effects (Farrell $\&$ Saloner, 1986). Although researchers have begun to shift their research focus to competitive strategies (Tseng, Teng, \& Chiang, 2005), their assumptions remain too restrictive. This study presents a general model for exploring methods of delivering superior value to customers in markets characterized by network effects.

The remainder of this paper is organized as follows. Section 2 reviews the theoretical background. Section 3 then describes the customer perceived value model. Subsequently, Section 4 elaborates ways for delivering superior customer value. Finally, Section 5 draws conclusions.

\section{THEORETICAL BACKGROUND}

The following first reviews the beginning and definitions on network effects. Then several variations of network effects are listed. Following the strategies applicable to markets with network effects, some counter-intuitive strategies are discussed. Then social welfare inefficiency from network effects and corresponding corrective activities are reviewed. The section then indicates the three papers that mostly relate to this study and discusses the differences between the current study and those papers.

\section{Definitions and Related Terminologies}

Researches on network effects might start at Katz and Shapiro (1985). Katz et al. (1985) used the term positive consumption externality to describe network effects as "the utility a user derives from consumption increases with the number of other users consuming the good" (Katz et al., 1985, p. 424) and then described it as "positive consumption benefits" (Katz et al., 1986, p. 823). Another definition says that "the fact that the value of a unit of the good increases with the number of units sold" (Economides, 1996, p. 678). Choi et al. (1997) argued that network externality "is no longer an externality if a market price already reflects the price of an external benefit or loss" (Choi et al., 1997, p. 4). They also proposed that network effects can better describe the targeted phenomenon than network externality (Choi et al., 1997, p. 4). This study adopts Choi et al.'s suggestion to use the term: network effects to describe the phenomenon.

While having similar but somehow different meanings, network effects also have many variations such as "positive demand externality" (Xie \& Sirbu, 1995), "indirect network externality" (Gupta, Jain, \& Sawhney, 1999), "complementary network externality" (Church \& Gandal, 1993), "congestion externality" (Westland, 1992), and "crossconsumer externality" (Holcombe \& Sobel, 2000). Some of them are similar to network effects but some are not. Detailed definitions and differences between them can be found

Copyright (C) 2007, Idea Group Inc. Copying or distributing in print or electronic forms without written permission of Idea Group Inc. is prohibited. 
in Chiang and Teng (2005). Having clear understanding upon those terms is essential for advancing knowledge on network effects.

\section{Strategies for Firms}

Strategies for e-businesses operating in markets with network effects include building alliances, obtaining first-mover advantages, managing customer expectations to increase profits (Shapiro \& Varian, 1999). Maybe the most famous strategy involving network effects is penetrative pricing. By setting an initially low price to penetrate a market with network effects, an e-business can quickly build a base of users and dramatically dominate the whole market when the user network size exceeds a "critical mass" (a threshold of network size for one network to have strong momentum to grow by having a size exceeding that threshold) (Bensaid \& Lesne, 1996; Shapiro \& Varian, 1998).

Conventional wisdoms may not apply to markets that are characterized by network effects. For example, permitting piracy can be beneficial to the market leader when pirates cannot offer the price for the technology but they can contribute utility to other legal users by interacting with them via the technology (Conner \& Remult, 1991). Furthermore, introducing clones (different but compatible products) may be harmful in conventional wisdoms but it could be beneficial in markets with network effects. Conner (1995) demonstrated that theoretically introducing clones increase profits. Choi et al. (1997) argued that the monopolistic position of Microsoft does not create inefficiency in terms of limited output and raising prices, contradictory to conventional wisdom on monopoly that monopoly always creates inefficiency.

\section{Inefficiencies and Corrective Activities}

Farrell et al. (1986) posited that a leader in markets with network effects will capture the whole market and theoretically, no challenger firm has any chance to survive in those markets. The competitive outcome is theoretically predicted, even when the challenger having a superior technology cannot survive, forming inefficiency in social welfare. Additionally, the monopolist (a market leader capturing a whole market) has incentives to offer products that are incompatible to their previous-version products to make the previously released products obsolete that is called planned obsolescence (Choi, 1994). The monopolist also has incentives to first offer poorer-quality products and then offer better-quality products as "upgrades" when information is asymmetrical (Padmanabhan, Rajiv, \& Srinivasan, 1997). The monopolist can also preannounce their upgrade version product to make competing technologies hardly attract prospect users (Farrell \& Saloner, 1986).

Economists argue that inefficiencies require governmental interventions to correct, reduce, or eliminate. Standard setting is one intuitive policy for preventing anti-socialwelfare R\&D (research and development) race. However, Kristiansen (1998) demonstrated that standard policy setting does the contrary, urging firms to compete more than ever to be the standard chosen by the government. Kristiansen also proved that forced licensing policy, which forces the winner license his or her technology to other firms, can correct the inefficiencies from network effects. Baake and Boom (2001) demonstrated that although firms prefer providing high quality products that are incompatible to the product of each other, the converter is always provided in Equilibrium. The existence of converter reduces social welfare inefficiency from network effects.

\section{Recent Studies}

Recent works on network effects have examined numerous topics, including product launch strategies (Lee \& O'Connor, 2003; Sun, Xie, \& Cao, 2004), pricing strategies (Chiang \& Teng, 2001; Gallaugher \& Wang, 2002), innovation and strategic activities (Ehrhardt, 2004; Ende \& Wijnberg, 2003), and strategies for beating the incumbents (leaders in markets with network effects) (Witt, 1997) or replacing the market leaders (Chiang \& Teng, 2003; Tseng 
et al., 2005). The thorough literature can be found in Chiang and Teng (2005).

Three papers are related especially closely to this study. First, Chiang et al. (2003) designed a model describing the scenarios for firms and customers in markets characterized by network effects. Chiang et al. also proposed a customertargeting strategy for the challenger could to compete with the market leader, by which the challenger targets some of the customers of the market leader and entices them away from the market leader's network. Once successful, the challenger may stimulate a chain reaction causing an exodus of customers away from the network of the market leader.

Second, Tseng et al. (2005) proposed the utility-threshold-raising strategy in which the challenger increases the utility thresholds (the minimal product utility for which consumers are willing to pay the price) of the customers of the market leader and thus reduces their net utilities in using the network of the market leader. Once their net utilities become negative, the customers will leave the network of the market leader and the challenger may gain a significant market share. Furthermore, Tseng et al. (2005) advanced the work of Chiang et al. (2003) by incorporating the concept of multiple adoptions (customers are willing to pay for using both the market leader's and the challenger's networks) into the model to describe the phenomenon of a customer using the networks of both the challenger and the market leader.

Third, Teng et al. (2006) developed a new concept, resilience, for describing the resistance of the network of a market leader against the attacks of the customer-capturing strategies of challengers, and identified three types of networks, namely high-resilience networks, medium-resilience networks, and low-resilience networks, based on their resilience values.

However, these works were based on simplified models for ease of analysis, and thus are of fairly limited practical use. For example, the price for using the network was assumed to be uniform for all customers, and the heterogeneity of customer utility thresholds was modeled as a simple linear function.
This study models the market situations in more general terms, and discusses the issue of delivering superior customer value in a broader sense. Therefore, the chief contribution of this study lies in providing more practical insights and suggestions for both challengers and market leaders in industries with network effects.

\section{MODELING THE CUSTOMER PERCEIVED VALUE WITH NETWORK EFFECTS}

According to Kotler (2003), customer perceived value (CPV) is the difference between total customer value and total customer cost. Total customer value includes four components: product value, services value, personnel value, and image value. Meanwhile, total customer cost includes monetary cost, time cost, energy cost, and psychic cost. This study applies the CPV concept of Kotler in the context of network effects.

\section{Total Customer Value}

This study first describes total customer value in the context of network effects. In the proposed model, each customer of a network enjoys two values. First, the stand-alone value (denoted by $V_{S}$ ), which is provided by the network facilities or infrastructures, regardless of whether others are using the same network. Second, the network value (denoted by $V_{N}$ ) provided by all other customers in the same network, which is generally an increasing function of the network size (namely, the number of customers adopting the network).

For simplicity, this study assumes that through participation in a network, every customer contributes a constant unit network value (denoted by $v_{n}$ ) to every other customer of the network. Therefore, the network value to a customer in a network with size $M$ (that is, with $M$ customers) is $V_{N}=(M-1) v_{n}$. Clearly, the network value increases with the network size. Therefore, the total customer value for a customer can be expressed as follows:

Copyright (C) 2007, Idea Group Inc. Copying or distributing in print or electronic forms without written permission of Idea Group Inc. is prohibited. 
total customer value $=$ stand-alone value + network value

$=V_{S}+V_{N}$

$=V_{S}+(M-1) v_{n}$.

\section{Total Customer Cost and Customer Perceived Value}

While enjoying the network values, every customer must bear the costs of network use, including the equipment purchasing cost, price for network participation, training costs, and the switching cost for changing a network. Notably, the price is not assumed to be uniform for all customers. Instead, a firm can set different prices for different customer segments.

Furthermore, the costs can vary for different customers. Here we denote the customer with the $i$ th-lowest cost as $C_{i}$. Hence, for a network of size $M$, customer $C_{l}$ has the lowest cost, and customer $C_{M}$ has the highest cost. That is, the customers are numbered in ascending order of total customer costs. An increasing function $f(i)$ can be used to represent the total customer cost for $C$, where $1+i-M$.

According to the definition of Kotler (2003), the customer perceived value (CPV) for $\mathrm{C}_{i}$ is defined as total customer value minus the total customer cost, or

CPV of customer $C_{i}$

$=$ total customer value - total customer cost

$=\left(V_{S}+(M-1) v_{n}\right)-f(i)$

Notably, for customers to remain in a network, their CPV must be non-negative; otherwise, the customer will suffer a loss from network participation.

\section{Summary of Notations}

The notations used in this study are listed next, along with a description of how they are used by the model.

1. $\quad \mathbf{V}_{\mathrm{s}}$ : The stand-alone value a customer gains by remaining in a network.

2. $\mathbf{v}_{\mathbf{n}}$ : The unit network value; that is, the value a customer contributes to every other customer in the same network.
3. $\mathbf{V}_{\mathrm{v}}$ : The network value to a customer remaining in a network.

4. M: The total number of prospective customers in the market.

5. $\quad \mathbf{C}_{\mathbf{i}}$ : The customer with the $i$ th-lowest total customer cost among all $M$ customers.

6. f(i): Total cost for customer $C_{i}$, where $1 \leq i \leq M$.

\section{DELIVERING SUPERIOR CUSTOMER PERCEIVED VALUE}

Customer perceived value can be increased by (1) increasing total customer value or (2) reducing total customer cost. This section discusses these two approaches, respectively.

\section{Increasing Total Customer Value}

Since total customer value comprises the sum of stand-alone value and network value, firms can deliver superior customer value by delivering higher stand-alone value or network value. While stand-alone value can only be increased by superior technologies or infrastructures, network value can be increased in several ways.

First, network value can be increased via a larger network size. Network size can be increased by either attracting more customers to a firm network, or by horizontal integration, including acquisitions, mergers, or strategic alliances. Since it is costly to acquire new customers, horizontal integration is generally a cheaper and more effective scheme for increasing network value. This is particularly true when the two networks are geographically separated, or when their customers belong to distinct market segments.

For example, two telecommunications companies can form a strategic alliance to create a mega-network so that their customers can enjoy favored intra-network rate when making phone calls within these two networks. Another practical example occurred in the USA when the employment Web Site CareerBuilder.com acquired HeadHunter.net to increase its market share and place itself in a better position to compete with the market leader Monster.com. 
Second, network value can be increased via increased unit network value, which can be achieved by designing services that are more valuable and by enhancing communications among customers.

For example, cell phone companies initially provided only conversation service, then added text messaging services, and recently have begun allowing video signals to be transmitted via cell phones. This evolution has increased the choices and communication channels available to users. Thus the value of $v_{n}$ has increased.

Another example was online auctions in China. During the first quarter of 2005, the trading value of the Chinese online auction Web Site Taobao.com exceeded that of eBay, despite Taobao.com having far fewer members than eBay. This phenomenon exists because Taobao.com delivers higher unitnetwork utility to its customers by customizing its services to suit the market conditions in China (Hu \& Lin, 2005). In fact, the profitability of Taobao.com attracted Yahoo! to invest one billion dollars in alibaba.com, the holding company of Taobao. com (Wang, 2005).

\section{Reducing Total Customer Cost}

As indicated in Section 3.2, we index the customers in ascending order of total customer costs and use an increasing function $f(i)$ to describe the total customer costs. A linear function with a larger slope implies higher heterogeneity among customers in their total costs, while a linear function with a smaller slope implies higher homogeneity among customers in their total costs.

A linear function is usually a convenient approximation. However, as the members of a network communicate and exchange information with each other for some time, the customers will become more homogeneous. In this case, a sub-linear (or concave) function may be a better approximation to their costs. In our model, therefore, we don't impose any specific form on the function, except the requirement that it is an increasing function of the index $i$, because we are numbering the customers in ascending order of the total customer costs. For explanatory purpose, however, we use both a linear and a sub-linear function to describe the reduction of the total customer costs in later discussion.

The total customer cost can be reduced by an offset (a constant amount) or by a ratio. First, a firm can reduce the total customer cost by an offset. For instance, a firm may offer a fixed amount of subsidies to customers, or may cut prices uniformly by a fixed amount. The result can be modeled as a decrease by an offset of the total customer cost. If the function $f(i)$ representing the total customer cost is a linear function, the effect of decreasing the total customer cost by an offset can be illustrated in Figure 1. If the function $f(i)$ is a sub-linear function (such as a square root function), the effect of reducing the total customer cost by an offset can be shown in Figure 2. In both figures, the original function is $f(i)$, represented by a dashed line (or dashed curve), and the reduced function is $f^{*}(i)$, represented by a solid line (or solid curve).

On the other hand, a firm can reduce the total customer cost by a ratio. For example, a firm may raise product or service standards to nullify the benefits offered by its competitors, or may include additional functions in the basic versions of their products or services. Raising the product or service standards will increase customer sensitivity to performance relative to prices. Since customers that have higher costs have invested more resources in using the network, they will respond more strongly to functional or technical improvements in the network. Consequently, the total costs of such customers will be reduced more than those of customers with lower total costs. The result can be modeled as a decrease of total customer costs by a particular ratio (i.e., multiplied with a number less than one). If the function $f(i)$ representing the total customer cost is linear, the effect of decreasing the total customer cost by a ratio can be illustrated in Figure 3. If the function $f(i)$ is a sub-linear function (such as a square root function), the effect of reducing the total customer cost by an offset can be 
Figure 1. Decreasing total customer cost by an offset for linear function $f(i)$

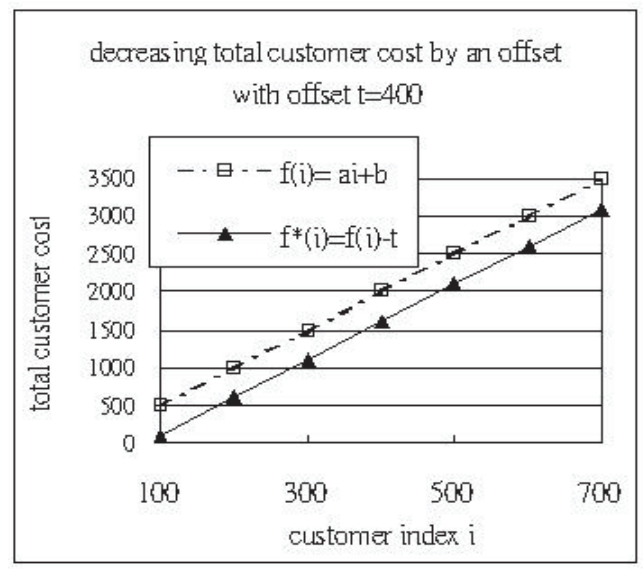

Figure 3. Decreasing total customer cost by a ratio for linear function $f(i)$

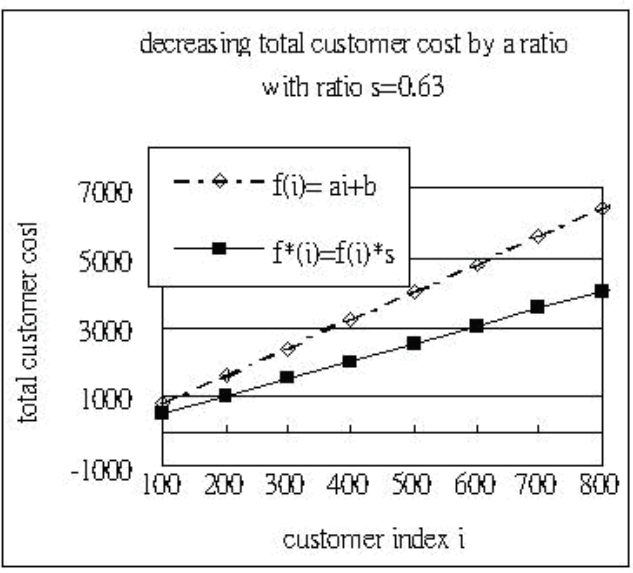

shown in Figure 4. In both figures, the original function is $f(i)$, represented by a dashed line (or dashed curve), and the reduced function is $f^{*}(i)$, represented by a solid line (or solid curve).

\section{CONCLUSION}

Network effects have been pervasive in various network industries, such as the computer hardware and software industries, telecommunication industries, and broadcasting and Cable TV industries. In the present age
Figure 2. Decreasing total customer cost by an offset for nonlinear function

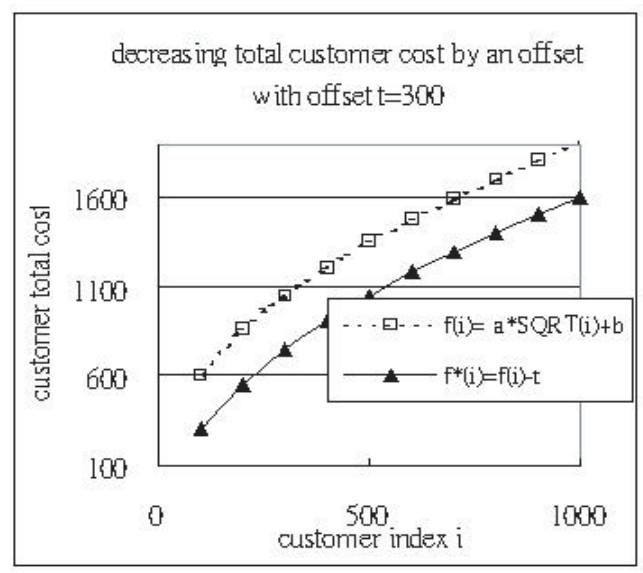

Figure 4. Decreasing total customer cost by a ration for nonlinear function $f(i)$

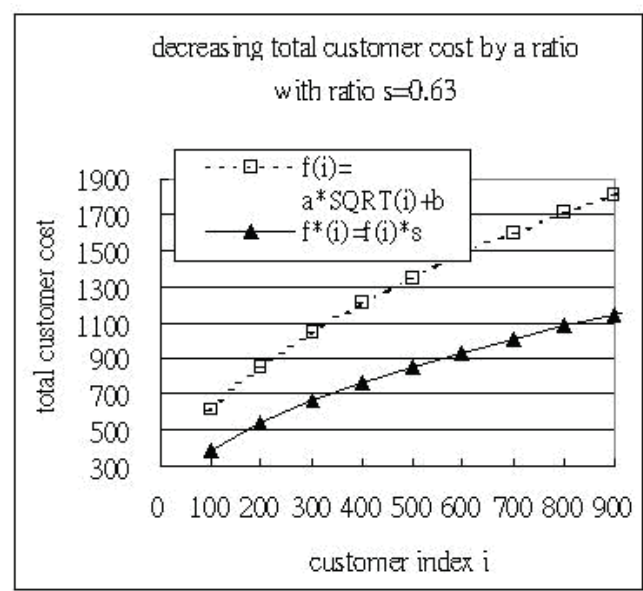

of e-commerce, network effects have become even more significant, as demonstrated by the overwhelming success of e-Bay auction compared to Yahoo! Auction in the U.S. and in Europe. To gain a competitive advantage in the context of network effects, firms must find ways to increase the value delivered to customers. This study provides significant insights to firms regarding these issues.

Specifically, our model makes two key achievements. The first one is on theoretical 
development. A more general model is proposed. The price no longer needs to be uniform for all customers, allowing firms to adopt differential pricing strategies. The heterogeneity of customer costs is no longer required to be a simple linear function, which reflects the fact that non-linearity is common in real life. Owing to reduced restrictions on the parameters, the current model can more accurately reflect the actual market situation.

The second one is on practical applications for firms in industries characterized by network effects, as in the information industry, telecommunication industry, and consumer electronics that require compatibility. Based on our model, two approaches - increasing customer value and reducing customer costs - are proposed for delivering superior customer value in the context of network effects.

To increase customer values, a firm can increase stand-alone value, network size, or unit network value. For examples, Internet service providers may consider horizontal integration to achieve a larger network size to create higher value to their customers. This has been practiced by Yahoo! Messenger and MSN when they allowed their customers to communicate with each other across these two systems.

Furthermore, customer cost could be reduced by either an offset or a ratio. A typical example can be found in the highly competitive cell phone service market in Taiwan. After the government enforced the number portability policy (which allows customers to transfer from one telephone operator to another without changing their telephone numbers), some firms (such as Taiwan Mobile) charge customers with a penalty fee when they switch to another operator carrying the original phone numbers. Start-up firms (such as Asia Pacific Telecom Group), on the other hand, are eager to subsidize new customers for this fee. This can be explained as reducing customer costs by an offset.

On the other hand, when a new technology is competing with existing technologies, subsidy alone will not work well. Substantial technological advances and benefits to customers are required to attract adopters whose total costs are higher. For example, Japan's NTT DoCoMo introduced the $3 \mathrm{G}$ cell phone standard W-CDMA, of which the technological advantage outweighed the drawback of incompatibility with existing cell phone standards. As a result, customers were willing to embrace the $3 \mathrm{G}$ services. This can be explained as reducing customer costs by a ratio.

This study provides a basis for modeling network effects using the concept of customer perceived value. Subsequent studies can use the model presented in this study to explain specific e-businesses successes and failures. Practitioners can design competitive strategies based on the two generic approaches presented here, namely increasing customer value, or reducing customer costs. Additionally, empirical research can provide estimates of the values of the model parameters to make the theories of network effects more solid and complete.

\section{ACKNOWLEDGMENT}

This chapter is sponsored by the National Science Council, Taiwan under contract: NSC93-2416-H-182-016. *Correspondence and reprint requests should be made to Ching-I Teng, chingit@mail.cgu.edu.tw.

\section{REFERENCES}

Baake, P., \& Boom, A. (2001). Vertical product differentiation, network externalities, and compatibility decisions. International Journal of Industrial Organization, 19(1,2), 267-284.

Bensaid, B., \& Lesne, J. P. (1996). Dynamic monopoly pricing with network externalities. International Journal of Industrial Organization, 14(6), 837-855.

Chen, Y. S., Chen, G., \& Wu, S. (2005). Issues and opportunities in e-business research: A Simonian perspective. International Journal of E-Business Research, 1(1), 37-53.

Chiang, M. H., \& Teng, C. I. (2001). Pricing strategies with network externalities between two groups of customers. NTU Management Review, 12(1), 1-36.

Chiang, M. H., \& Teng, C. I. (2003). Installed

Copyright $($ 2007, Idea Group Inc. Copying or distributing in print or electronic forms without written permission of Idea Group Inc. is prohibited. 
base collapsing strategies with network externalities. Journal of Management, 20(5), 829-857.

Chiang, M. H., \& Teng, C. I. (2005). Consumption externalities: Review and future research opportunities, Electronic Commerce Studies, 3(1), 15-38.

Choi, J. P. (1994). Network externalities, compatibility choice, and planned obsolescence. Journal of Industrial Economics, 42(2), 167-182.

Choi, S. Y., Stahl, D. O., \& Whinston, A. B. (1997). Is Microsoft a Monopolist? Brazilian Electronic Journal of Economics, 1(0), December 10.

Chou, C. F., \& Shy, O. (1990). Network effects without network externalities. International Journal of Industrial Organization, 8(2), 259-270.

Church, J., \& Gandal, N. (1993). Complementary network externalities and technological adoption. International Journal of Industrial Organization, 11(2), 239-260.

Conner, K. R. (1995). Obtaining strategic advantage from being imitated: When can encouraging "clones" pay? Management Science, 41(2), 209-225.

Conner, K. R., \& Rumelt, R. P. (1991). Software piracy: An analysis of protection strategies. Management Science, 37(2), 125-139.

Economides, N. (1996). The economics of networks. International Journal of Industrial Organization, 14(6), 673699.

Ehrhardt, M. (2004). Network effects--Standardization and competitive strategy: How companies influence the emergence of dominant designs. International Journal of Technology Management, 27(2,3), 272.

Ende, J., \& Wijnberg, N. (2003). The organization of innovation and market dynamics: Managing increasing returns in software firms. IEEE Transactions on Engineering Management, 50(3), 374.

Farrell, J., \& Saloner, G. (1986). Installed base and compatibility: Innovation, product pre-announcements, and predation. American Economic Review, 76(5), 940-955.

Farrell, J., \& Saloner, G. (1992). Converters, compatibility, and control of interfaces, Journal of Industrial Economics, 40(1), 9-35.

Gallaugher, J. M., \& Wang, Y. M. (2002). Understanding network effects in software markets: Evidence from Web server pricing. MIS Quarterly, 26(4), 303-327.

Gupta, S., Jain, D. C., \& Sawhney, M. S. (1999). Modeling the evolution of markets with indirect network externalities: An application to digital television. Marketing Science, 18(3), 396-416.

Holcombe, R. G., \& Sobel, R. S. (2000). Consumption externalities and economic welfare. Eastern Economic Journal, 26(2), 157-170.

Hu, J., \& Lin, H. (2005). The online auction Web Site that beats e-Bay in China. Business Weekly, 921, July 18-24, 2005 (in Chinese).

Katz, M. L., \& Shapiro, C. (1985). Network externalities, competition, and compatibility. American Economic Review, 75(3), 424-440.

Katz, M. L., \& Shapiro, C. (1986). Technology adoption in the presence of network externalities. Journal of Political Economy, 94(4), 822-841.

Kotler, P. (2003). Marketing management. Prentice Hall.

Kristiansen, E. G. (1998). R\&D in the presence of network externalities: Timing and compatibility. Rand Journal of Economics, 29(3), 531-547.

Lee, Y., \& O’Connor, G. C. (2003). New product launch strategy for network effect products. Journal of the Academyof Marketing Science, 31(3), 241-255.

Padmanabhan, V., Rajiv, S., \& Srinivasan, K. (1997). New products, upgrades, and new releases: Arationale for sequential product introduction, Journal of Marketing Research, 34(4), 456-472.

Shapiro, C., \& Varian, H. R. (1998). Information

Copyright $($ C 2007, Idea Group Inc. Copying or distributing in print or electronic forms without written permission of Idea Group Inc. is prohibited. 
rules. HBS Press.

Shapiro, C., \& Varian, H. R. (1999). The art of standard wars. California Management Review, 41(2), 8-32.

Sun, B., Xie, J., \& Cao, H. H. (2004). Product strategy for innovators in markets with network effects. Marketing Science, 23(2), 243.

Teng, C. I., Tseng, F. C., \& Chiang, D. M. (2006). Customer-capturing strategies: The way to replace existing technology characterized by network effects. Technovation, 26(12), 1384-1389.

Tseng, F. C, Teng, C. I., \& Chiang, M. H. (2005). Competing on utility thresholds: The way to capture markets characterized by network effects. Proceedings of the
International Conference on Business and Information, Hong Kong, July 2005.

Wang, X. P. (2005). Yahoo! invests in alibaba. com. Commercial Times, Aug. 12, 2005 (in Chinese).

Westland, J.C.(1992). Congestion and network externalities in the short run pricing of information system services. Management Science, 38(7), 992-1009.

Witt, U.(1997). "Lock-in"vs. "critical masses"-industrial change under network externalities. International Journal of Industrial Organization, 15(6), 753-773.

Xie, J., \& Sirbu, M. (1995). Price competition and compatibility in the presence of positive demand externalities. Management Science, 41(5), 909-926.

Fan-Chen Tseng is an associate professor in the Department of Information and Electronic Commerce at Kainan University (KNU), Taiwan R.O.C. He received his BSEE and MSEE degrees from the Department of Electrical Engineering at Taiwan University in 1984 and 1986, respectively. After that, he was with the Swire Group (Taiwan), United Microelectronics Corporation $(U M C)$, and National Yi-Lan University. He received his PhD in information engineering at Taiwan University in 2002. His current research and teaching interests are in the area of data mining and information retrieval. Recently, his interests also cover the area of electronic commerce management and Internet marketing.

Ching-I Teng is an assistant professor in the Graduate Institute of Business Administration, Chang Gung University, Taiwan. He received his PhD in management from National Taiwan University in 2002. His research interests include network effects, electronic commerce, and consumer psychology and behavior in cyberspace. He has papers published in Technovation, NTU Management Review, Journal of Management, and Electronic Commerce Studies.

David M. Chiang is professor of operations management and logistics in the Department of Business Administration at The National Taiwan University, Taipei, Taiwan. He earned his PhD in management science from The University of Iowa in 1992. Dr. Chiang research interests include supply chain management, production scheduling, and inventory management. He has published in Annals of Operations Research, Journal of Management and System, BJU International, Journal of Management.

Copyright $($ C 2007, Idea Group Inc. Copying or distributing in print or electronic forms without written permission of Idea Group Inc. is prohibited. 
Reproduced with permission of the copyright owner. Further reproduction prohibited without permission. 